\title{
Current Management of Pleural Disorders
}

\author{
Jack Kastelik \\ Department of Respiratory Medicine, Hull and East Yorkshire NHS Trust, \\ University of Hull, Hull York Medical School, Castle Hill Hospital, Castle Road, Cottingham HU16 5JQ, UK
}

Received 2012-06-03, Revised 2013-01-23; Accepted 2013-05-07

\begin{abstract}
A wide range of conditions can present with plural involvement. For this reason patients with pleural disorders may be seen by a number of different specialists. The most common pleural disorders include pleural effusion and pneumothorax. Pleural effusion and pneumothorax are defined as accumulation within the pleural space of fluid and air respectively. The most common disorders responsible for over $90 \%$ of pleural effusions include congestive heart failure, malignancy, infection and pulmonary embolism. The pneumothorax can be divided into primary spontaneous, secondary, iatrogenic or traumatic. This review article will discuss our current understanding behind the pathophysiology of pleural effusion. Common causes and less common conditions resulting in pleural effusion will be described. Investigations and management of patients with pleural dsiorders will also be discussed. In addition, recent advances in our understanding of etiology and management of pneumothorax will be covered. Investigations and management of pleural disorders require an understanding of the underlying pathology as well as the expertise in currently available interventional procedures. The main challenge remains to manage patients in accordance to the current guidelines, which is best achieved through specialist services. However, the knowledge related to pleural disorders remains of importance to many specialists.
\end{abstract}

Keywords: Pleura, Pleural Effusion, Pneumothorax

\section{INTRODUCTION}

Pleural disorders remain a common clinical problem relevant to a number of specialists (Du Rand and Maskell, 2010; Light, 2011a). For example, around a quarter of referrals to respiratory clinics are related to pleural diseases (Light, 1997). The prevalence of pleural disorders has been estimated at around 3000 people per million population each year (Du Rand and Maskell, 2010). The annual incidence of pleural effusion in the United States of America (USA) may be as high as 1 million (Light, 1997; 2011b). The most common disorders responsible for over $90 \%$ of diagnosed pleural effusions include congestive heart failure, malignancy, infection and pulmonary embolism (Marel et al., 1993). In epidemiological studies congestive heart failure and pulmonary embolism were responsible for pleural effusions in 800,000 and between 300,000 to 500,000 cases annually in the USA respectively (Light, 2002; 2010; Marel et al., 1993; Porcel and Light, 2008). Malignant pleural effusion affects more than 175,000 people each year in the USA and more than 40,000 in the United Kingdom (Bennet and Maskell, 2005). Pulmonary infection such as pneumonia may result in pleural effusion in around $40 \%$ of patients with an estimated 60,000 cases of pleural infection per year in the USA and its associated mortality of approximately $15 \%$ (Chapman and Davies, 2004; Ferguson et al., 1996; Light, 2006a; Sahn, 1993). In the USA between 1993 and 2003 there were 7549 cases of pleural effusion due to tuberculosis representing $18 \%$ of all cases (Baumann et al., 2007). The incidence of pneumothorax has been described between 18-28/100,000 cases per annum for men and $1.2 / 100,000$ for women (MacDuff et al., 2010). In the UK, hospital admissions due to pneumothorax have been estimated at $16.7 / 100,000$ per year for men and 5.8/100,000 per year for women (Gupta et al., 2000). The same rates for a person consulting a physician were 24.0/100,000 each year for men and 9.8/100,000 each year for women. Slightly lower rates at 7.9/100,000 per year were reported in a study from the USA (Melton et al., 
1979). This review will discuss the current understanding, investigations and management of common pleural disorders such pleural effusion, pneumothorax, infection of pleura as well as some of the less common conditions that may affect the pleura.

\subsection{Characteristics of Pleural Fluid}

The pleura is a monolayer of mesothelial cells covering the lung and the inner surface of the chest cavity and creating the pleural space (Finley and Rusch, 2011). In healthy adults the volume of pleural fluid has been reported as $0.26 \pm 0.1 \mathrm{~mL} \mathrm{~kg}^{-1}$ with its main role being to lubricate the visceral and parietal pleural surfaces allowing for the breathing movement (Noppen, 2001). There are over 50 causes of pleural effusions. Pleural effusion occurs when there is more fluid entering the pleural space than that being removed (Porcel and Vives, 2006). This can take place when there is an increased formation of the fluid or reduced re-absorption (Hooper et al., 2010a). The precise mechanisms of pleural fluid formation have not yet been fully understood but vary depending on the aetiology. For example, increased pulmonary capillary pressure may be seen in cardiac failure, increased permeability in infection, decreased oncotic pressure in hypoalbuminemia, increased membrane permeability and obstructed lymphatic flow in malignancy (Porcel and Light, 2006; Hooper et al., 2010b). Light et al. (1972) described simple diagnostic criteria to differentiate plural effusions into trasudates and exudates. These 'Light's criteria' rely on sampling pleural fluid and analysing pleural effusion and serum ratio of protein and Lactate Dehydrogenase (LDH). Over the years these criteria have been proved to have diagnostic accuracy of $96 \%$ in separating transudates and exudates and compared favorably with other methods such as assessment of pleural fluid cholesterol or albumin (Heffner et al., 1997; Romero et al., 2000). The more common causes of transudative effusions are congestive heart failure and liver cirrhosis and those of exudative effusions malignancy, infection and pulmonary embolism.

In healthy adults, pleural fluid contains less than 1800 cells $\mu \mathrm{L}^{-1}$; mainly mesothelial cells, macrophages (75\%) and lymphocytes (23\%) as well as small amount of eosinophils and neutrophils (Noppen, 2001). Pleural fluid is normally alkaline at $\mathrm{pH}$ around 7.6. However in some conditions such as empyema, tuberculosis, cancer, rheumatoid arthritis or drug reactions pleural fluid $\mathrm{pH}$ may be below 7.2 (Good et al., 1980). In addition, to cellular component pleural fluid also contains bicarbonate, LDH, proteins and glucose (Noppen, 2001).
There are a number of disorders that may result in abnormal cell composition of pleural fluid. Neutrophils are the most common cells in pleural effusion due to acute conditions and the presence of lymphocytes suggests more chronic process. Thus exudates with predominance (over $80 \%$ of the total cell count) of lymphocytes are suggestive of tuberculosis, lymphoma, leukaemia, rheumatoid arthritis or post cardiac surgery related pleural effusions (Sahn, 1995). Neoplastic pleural effusion can also be characterised by lymphocyte predominance usually $50-70 \%$ of total cell count. As most transudates are lymphocytic predominant, congestive cardiac failure remains the most common cause of this type of pleural effusion. Eosinophilic pleural effusion defined as more than $10 \%$ of total cell count is relatively rare and may be seen in up to $16 \%$ of exudative effusions with the most common causes being hemothorax, pneumothorax, malignancy, infection, drug reactions, pulmonary embolism or benign asbestos related pleural effusions (Martinez-Garcia et al., 2000; Kalomenidis and Light, 2003). Certain characteristics of cell count and other measurements such as low $\mathrm{pH}$ my point out towards specific conditions. For example, in the context of low pleural fluid $\mathrm{pH}$, increased neutrophil count would suggest empyema, raised eosinophil count drug reaction and increased lymphocytes count tuberculosis or cancer. Rarely chyle a lymphatic fluid enriched in lymphocytes, immunoglobulins and lipids may be detected in the pleural space (Townshend et al., 2007). Chylothorax has been described mainly due to trauma, lymphoma and less frequently due to Lymphangioleiomyomatosis (LAM) or yellow nail syndrome. The treatment may include a low fat diet containing medium chain triglycerides, which reduces production of chyle or surgical ligation of the duct, which may be successful in up to $90 \%$ of patients.

\subsection{Common Causes of Transudative Pleural Effusion}

Cardiac failure and liver disease related pleural effusions are most commonly classified as transudates with the proposed underlying mechanisms being low albumin level and ascitic fluid movement across the diaphragmatic defect as a result of an increased intraabdominal pressure (Kinasewitz and Keddissi, 2003). The management of pleural effusion due to liver disease may be difficult and relies on the treatment of its cause however, in refractory cases pleurodesis, indwelling 
pleural catheter or repeated thoracocenthesis may be required (Milanez de Campos et al., 2000; Gur et al., 2004). Overall the most common cause of transudate remains congestive cardiac failure and in this context pleural effusions are usually bilateral although in a fifth of cases small unilateral effusions can occur (Porcel and Light, 2006). Interestingly a quarter of pleural effusions on the background of cardiac failure may be mislabelled as exudates (Johnson, 2000; Bielsa et al., 2012). In those patients therefore measuring the albumin rather than the protein gradient may be more accurate. Recent studies have shown that pleural fluid $\mathrm{N}$ terminal Pro-Brain Natriuretic Peptide (pro-BNP) levels may have high sensitivity and specificity for diagnosing cardiac failure related pleural effusion (Porcel et al., 2004). In the context of cardiac disease, pleural effusion related to Coronary Artery Bypass Grafting (CABG) surgery should also be mentioned. In most cases the amount of fluid is small and resolves spontaneously. Light et al. (1999) described two types of pleural effusion that occur post CABG surgery. The first type most likely traumatic in origin occurs within 28 days from CABG surgery and is usually blood stained and eosinophils predominant. The second type is most likely immunologic in origin and occurs at a later stage over 30 days following surgery and is lymphocytic in nature. In those patients, other causes of pleural effusion need to be excluded including infection, chylothorax, cardiac failure or pulmonary embolism. Pleural effusion due to isolated right heart failure has also been described and can occur with idiopathic pulmonary arterial hypertension or in association with connective tissue diseases (Brixey and Light, 2011; Luo et al., 2011).

\subsection{Malignant Pleural Effusion}

Malignancy remains one of the most common causes of pleural effusion (Roberts et al., 2010). Pleural effusions occur in around half of patients with metastatic malignancy and usually presents with dyspnoea or chest pain (Shaw and Agarwal, 2004). Over three quarters of malignant pleural effusions are secondary to neoplasm of the lung, breast, ovaries, lymphomas, genitourinary and gastrointestinal tract (Heffner and Klein, 2008). Mesothelioma remains the most common primary pleural cancer associated with pleural effusion. Malignant pleural effusion characterized by the presence of cancer cells in the pleural space usually defines advanced stages of cancer with median survival around 3 to 6 months with palliation remaining the main goal of treatment (Lanken et al., 2008). It is worth remembering that patients with cancer can develop pleural effusion without the presence of cancer cells in the pleural fluid, so called paraneoplastic pleural effusion, as well as those associated with concomitant conditions such as pulmonary embolism or cardiac failure (Heffner, 2008). Malignant pleural effusions are exudates by nature due to the high protein and the LDH levels although they can present occasionally as transient transudates in cases of carcinomatous lymphangitis (Fernandez et al., 2000). Thoracocenthesis which is nowadays performed under ultrasound guidance allows for sampling of pleural fluid for cytological analysis (Kastelik et al., 2009; Phillip et al., 2003). The diagnostic yield from a single plural fluid cytological analysis has been quoted as up to $60 \%$ overall but with a much lower yield at only $20-30 \%$ in cases of mesothelioma. Occasionally, additional tests such as pleural fluid amylase may be of help (Fahim and Kastelik, 2010). A repeat aspiration only slightly improves the diagnostic yield. Thoracoscopy, surgical or medical, has been perceived as the 'gold standard' with a diagnostic yield of 93-97\% (Rodriguez-Panadero, 2008). Medical thoracoscopy also called 'pleuroscopy' is performed under local anaesthesia and conscious sedation (Rodriguez-Panadero et al., 2006). Medical thoracoscopy involves insertion of a trocar through which then an optical telescope, a light source and biopsy forceps can be introduced into the pleural cavity. Surgical Video Assisted Thoracosopic Surgery (VATS) is performed by a thoracic surgeon in an operating theatre under general anaesthesia. Both techniques allow for drainage of the pleural fluid, pleural biopsies under direct vision and talc pleurodesis (Rodriguez-Panadero et al., 2006).

The management of patients with malignant pleural effusion requires expertise and a multidisciplinary approach in order to provide individualised high quality treatment that is in accordance with the current guidelines (Roberts et al., 2010). Patients with poor performance status who are expected to survive less than 3 months can be managed by performing repeated thoracocentheses if there is evidence of improvement in their symptoms (Heffner, 2010). In the majority of patients fluid will re-accumulate within 1 month, therefore thoracocenthesis is not an optimal therapy for patients with longer expected survival who may require more definitive treatment including medical or surgical pleurodesis or an insertion of indwelling pleural catheter (Heffner, 2008; Rodriguez-Panadero and Romero-Romero, 2011; Viallat et al., 1996). Pleurodesis is a procedure that allows for symphysis between the visceral and parietal pleura that prevents the accumulation of the pleural fluid (Rodriguez-Panadero 
and Montes-Worboys, 2012). Talc is the most effective chemical pleurodesis agent and has been shown to be safe and effective treatment of malignant pleural effusion (Dresler et al., 2005; Janssen et al., 2007). Medical pleurodesis using chest drain and talc slurry is the least invasive method with acceptable success rates (Gondker et al., 2011; Dresler et al., 2005). There is evidence that short term chest tube drainage of malignant pleural effusion followed by talc slurry pleurodesis is as effective as longer protocols with the benefits of reduced hospital length of stay (Goodman and Davies, 2006; Spiegler et al., 2003). Thoracoscopy with talc poudrage pleurodesis has been shown to be possibly a more effective method for managing pleural effusion (Janssen et al., 2007). A number of studies suggest a success rate from thoracoscopy and talc poudrage at 1 month at $84 \%$ compared with those of $60 \%$ for pleurodesis with talc slurry through a chest drain (Rahman et al., 2010). However Dresler et al. (2005) demonstrated in a randomised controlled study that success rates at 1 month for thoracoscopic talc poudrage of $78 \%$ and that for talc slurry through intercostal chest drain of $71 \%$. Although patients with lung or breast cancer had significantly higher success rates for thoracoscopic pleroudesis at $82 \%$ compared with that using intercostal chest drain and talc slurry. Comfort, safety and symptoms of fatigue seemed to favor thoracoscopy. Another option for the management of malignant pleural effusion involves insertion of small bore indwelling pleural catheters, which can be performed on outpatient basis and have been shown to improve quality of life and symptoms of breathlessness and have low complication rates (Putnam et al., 2000). The indwelling pleural catheters have acquired wide use especially in patients with malignant pleural effusion and trapped lung, those who had failed pleurodesis and have been shown to have $45 \%$ rates of spontaneous pleurodesis (Putnam et al., 2000; Van Meter et al., 2011). In a recent study indwelling pleural catheters were placed during medical thoracoscopy with talc pleurodesis with success rates quoted at $92 \%$ and associated low hospitalization stay of 1.79 days (Reddy et al., 2011).

\subsection{Pleural Effusion Due to Pulmonary Embolism}

Computed tomography pulmonary angiogram (CTPA) can detect pleural effusion in around $47 \%$ of patients with pulmonary embolism (Porcel et al., 2007; Bynum and Wilson, 1978). The mechanisms of pleural effusion in the context of pulmonary embolism are not fully understood but may be related to the presence of pulmonary infarction (Light, 2010). The fluid is usually a neutrophil predominant exudate (Porcel et al., 2007). Typically, pleural effusions are small and unilateral occupying less than $30 \%$ of the hemothorax, appear soon after the symptoms of thromboembolism have began and tend to reach their maximal size early in the course of the disease. Pulmonary infarction may be associated with larger pleural effusions that may clear more slowly (Bynum and Wilson, 1978). In patients who had massive pulmonary embolism pleural effusion may be seen on a CTPA in around $79 \%$ of cases (Findik et al., 2008). In cases when the diagnosis of pulmonary embolism was delayed pleural effusion may be loculated (Porcel et al., 2007). It is important to remember that potential complications of pleural effusion due to pulmonary embolism include hemothorax and infection. Therefore if pleural effusion on the background of pulmonary embolism is increasing in size diagnostic thoracoenthesis should be considered.

\subsection{Pleural Infection}

Whilst pleural infection remains relatively common, due to the advances in imaging techniques and antimicrobial therapies, the diagnosis and the outcomes of this condition have improved significantly (Davies et al., 2010; Heffner et al., 2010; Wrightson and Maskell, 2012). From the bacteriological aspects, for community acquired pleural infection the most common detected agents include Streptococcus milleri, Streptococcus pneumonia, Staphylococcus aureus and anaerobes (Maskell et al., 2005). For hospital acquired pleural infection the following bacteria have been commonly reported; staphyloccci including Methicillin-Resistant Staphylococcus Aureus (MRSA), gram negative bacteria such as Escherichia coli or Klebsiella species as well as anaerobes (Maskell et al., 2006). Light (1995) suggested a classification of parapneumoninc effusion and empyema into 7 classes depending on the size of the effusion, $\mathrm{pH}$ measurements, LDH levels and microbiological characteristics. The current guidelines describe three developmental stages of empyema associated with pneumonia; a simple exudate, fibrinopurulent stage and organising stage with scar tissue formation (Davies et al., 2010). Although parapneumonic effusion of less than 10 to $20 \mathrm{~mm}$ in depth, should resolve spontaneously majority of parapneumonic effusions would require sampling (Skouras et al., 2010). The sampling should be performed under image usually thoracic ultrasound guidance. Pleural fluid analysis including $\mathrm{pH}$, glucose, $\mathrm{LDH}$, microbiology including cultures for tuberculosis 
and cytology provides important information regarding the management. The characteristics of complicated parapneumonic effusion include $\mathrm{pH}$ less than 7.2, glucose less $2.2 \mathrm{mmoL} \mathrm{L} \mathrm{L}^{-1}\left(40 \mathrm{mg} \mathrm{dL}^{-1}\right)$ and LDH greater than $1000 \mathrm{IU} \mathrm{L}^{-1}$ with empyema being defined by presence of frank pus. It should be noted that occasionally $\mathrm{pH}$ can be alkalotic in cases of empyema due to proteus species. There is evidence that in order to increase the diagnostic yield by around a fifth the aspirated plural fluid should not only be collected as standard culture but also inoculated into aerobic and anaerobic blood culture bottles (Menzies et al., 2011).

Complicated parapneumonic effusion and empyema will require intercostal chest drain insertion. Whilst historically a large bore chest drain was recommended recent evidence suggests that smaller size 10-14 F may be adequate in managing those patients (Light, 2011b). Antibiotic therapy should be initiated as soon as pleural infection is identified. The choice of antimicrobial agents will depend on the microbiological culture results. In community acquired pleural infection aminopenicillins with beta-lactamase inhibitor may be a good first choice of treatment although other antibiotics such as carbapenems, clindamycin or cephalosporins can also be considered. For hospital acquired pleural infection antimicrobial agents should also include MRSA cover until confirmation of pathogens from microbiological results becomes available (Maskell et al., 2006). If these measures are not sufficient and sepsis and the infected fluid are not controlled a proportion of patients may require surgery in the form of thoracoscopy with breakdown of adhesions or thoracotomy with decortications (Petrakis et al., 2010). Surgical options for an early usually fibrinopurulent stage of empyema may include VATS and in organised phase open thoracotomy and decortications may be the only option. The timing of surgery is a very important factor in influencing the mortality from empyema. There has been a long debate whether thrombolytic agents are of use in the treatment of pleural infection. In a recent study, intra-pleural tissue Plasminogen Activator (t-PA) and DNase were shown to reduce frequency of surgical referrals, duration of hospital stay and improved the drainage of infected fluid in patients with pleural infection (Rahman et al., 2011). Interestingly, treatment with DNase alone or t-PA alone was ineffective and the authors concluded that in patients in whom standard therapy failed a combination of intra-pleural t-PA and DNase may be considered. The outcomes of pleural infection with modern management are generally good with pleural thickening seen in $14 \%$ of cases, fortunately with very little functional impairment and the long term mortality of around 14\% mainly due to co-morbidities (Davies et al., 1999; Farjah et al., 2007; Light, 2006a).

\subsection{Pleural Effusion Due to Less Common Causes}

There are a number of conditions causing pleural effusion, however amongst the less common causes connective tissue disorders, medications and pleural effusion in immunocompromised host are of particular interest. Around $4 \%$ of patients with rheumatoid arthritis may develop pleural effusion usually associated with the thickening of the visceral and parietal pleura (Avnon et al., 2007). Pleural effusion in rheumatoid arthritis is characterised by a low $\mathrm{pH}$, low glucose with cell composition varying from lymphocyte to neutrophil predominant (Balbir-Gurman et al., 2006; Hunninghake and Fauci, 1979). In half of patients pleural effusion improves spontaneously within 4 weeks but in a fifth it may persist for over 12 months. Occasionally, patients with rheumatoid arthritis may develop chronic pleural effusion with a high content of lipids so called pseudochylus effusion. In addition, patients with rheumatoid arthritis have an increased risk of developing empyema. Pleural involvement may also be seen in Systemic Lupus Erythematosus (SLE) with around $10 \%$ of cases of pleuritis being reported as the first manifestation of this disease (Pines et al., 1985). Pleural effusion associated with SLE is characterised by reduced levels of complement and raised fluid to serum antinuclear antibody ratio of above 1. Pleural effusion has also been reported in association with conditions such as systemic sclerosis or dermatomyositis (Hunninghake and Fauci, 1979).

Clinicians should also be aware of pleural effusion due to medications and that occurring in immunocompromised host. Medications such as methotraxate, amiodarone, phenytoin or pergolide have been shown to cause pleural diseases including pleural thickening or pleural effusion (Kastelik et al., 2002). There are number of conditions that can result in pleural disorders in immunocompromised patients such as parapneumonic effusion, tuberculosis, Kaposi's sarcoma, thoracic non-Hodgkin lymphoma, primary effusion lymphoma and spontaneous pneumothorax (Beck, 1998; Afessa, 2000; 2001). There have been a small number of patients describe who have bilateral pleural effusions so called Contarini's syndrome when different cause for pleural fluid on each side can be confirmed (Porcel et al., 2012). In those cases common findings are parapneumonic effusion with contralateral transudate due to cardiac failure or malignant pleural effusion due to for example, ovarian cancer on one side with contralateral chylus pleural effusion as a result of 
obstruction of thoracic duct from metastatic deposits (Lawton et al., 1985; Kutty and Varkey, 1978).

\subsection{Investigations of Pleural Effusion}

Investigation of pleural effusion should involve a systematic approach (Porcel and and Vives, 2006; Hooper et al., 2010a). Clinical history remains important in determining the underlying cause of pleural effusion and should include assessment of medications and occupational aspects such as asbestos exposure. Chest radiograph can detect pleural effusion greater than 200 $\mathrm{ml}$ in volume. In recent years bedside thoracic ultrasonography has become more widely performed by pulmonary specialists (Kastelik and Arnold, 2012). Thoracic ultrasound allows for diagnosis and characterisation of pleural effusion (Feller-Kopman, 2009; Koenig et al., 2011). More importantly there is good evidence to suggest that ultrasound guided pleural procedures is associated with lower rates of complications (Grogan et al., 1990; Jones et al., 2003). When performed by an experienced operator certain findings on thoracic ultrasound may suggest the origin of pleural effusion such as malignancy, which may be supported by the presence of more than $1 \mathrm{~cm}$ pleural thickening, pleural nodularity and diaphragmatic thickening of more than $7 \mathrm{~mm}$ (Qureshi et al., 2009). Similarly, specific findings on CT may suggest the origin of pleural effusion such as pulmonary embolism, infection or malignancy. Thus presence on CT images of pleural nodules, nodular thickening infiltration of the diaphragm or circumferential or mediastinal pleural thickening may support the diagnosis of malignancy (Arenas-Jimenez et al., 2000).

Thoracocenthesis allows for sampling of pleural effusion and biochemical, cytological and microbiological analysis that assists in establishing the underlying cause. In around $15 \%$ of cases with exudates pleural effusion diagnosis cannot be reached (Light, 2006b). Medical thoracoscopy under local anaesthesia has been shown not only to improve diagnostic rates but also to influence the management outcomes in the majority of patients (Blanc et al., 2002; Harris et al., 1995). The diagnostic yields from pleural biopsies taken during medical thoracoscopy are at around 97\% and for this reason this procedure is becoming more widely used in the investigations of patients with pleural effusion (Lee et al., 2010; Rahman et al., 2010; Sakuraba et al., 2006). Ideally, patients with pleural disorders should be investigated through specialist pleural services that include designated pleural clinics to provide rapid diagnosis using ambulatory manner and limited number of invasive procedures (Hooper et al., 2010b). The specialist pleural services should be run by pulmonologists with support from radiologists, pathologists, oncologist and thoracic surgeons. This multidisciplinary approach to manage patients with pleural disorders would aim to provide rapid diagnosis and the most appropriate therapy.

\subsection{Pneumothorax}

Pneumothorax defined as an air in the pleural cavity can be divided into primary secondary or traumatic (MacDuff et al., 2010; Tschopp et al., 2006). Patients usually present with pleurictic chest pain and dyspnoea and diagnosis is confirmed on a chest radiograph. Pneumothorax has to be distinguished from conditions such as pneumomediastinum (Faruqi et al., 2006). Primary spontaneous pneumothorax is not associated with underlying lung diseases whereas secondary pneumothorax occurs on the background of existing lung disorders most commonly chronic obstructive pulmonary disease, cystic fibrosis or interstitial lung diseases. Recent evidence suggests that primary spontaneous pneumothorax may be associated with changes within the pleura as well as being caused by the rupture of the blebs or bullae with the most commonly described abnormalities including emphysema like changes, plural inflammation and porosity which are areas of inflammation on the visceral pleura most likely due to mesothelial cells being replaced by inflammatory cells (Grundy et al., 2012; Haynes and Baumann, 2011). However, there is evidence that in patients with primary spontaneous pneumothorax there is an increased risk of recurrence on the ipsilateral as well as contralateral site if the blebs are confirmed on the CT imaging (Sihoe et al., 2000; Huang et al., 2007).

International guidelines provide recommendations for the management of patients with pneumothorax that include either observation, thoracocenthesis with aspiration of air or insertion of an intercostal chest drain depending on symptoms and the size of the pneumothorax (Baumann et al., 2001; Macduff et al., 2010). Patients with small pneumothorax without significant breathlessness as well as a selected group of patients with a large pneumothorax who are asymptomatic can be observed and may not require any intervention. For patients with large primary spontaneous pneumothorax an aspiration using 16-18 G cannula can be considered and if not successful an insertion of chest drain should be performed. British Thoracic Society (BTS) guidelines recommend for a large over $2 \mathrm{~cm}$ in 
size primary spontaneous pneumothorax and for the secondary pneumothorax chest drain insertion although for a smaller size pneumothorax a simple aspiration may be considered (Macduff et al., 2010). The American College of Chest Physicians (ACCP) guidelines differ from the BTS guidelines with regards to their description of a large pneumothorax, which they describe as equal as or more than $3 \mathrm{~cm}$ apex-to-cupola distance. More importantly the ACCP panel overall for treatment of pneumothorax favored insertion of intercostal chest drain with a simple aspiration being thought to be rarely appropriate. The reason for this difference reflects the paucity of data from randomised control studies. The recurrence of primary spontaneous pneumothorax after treatment with insertion of chest drain remains between 30 and $55 \%$ and it increases to over $62 \%$ for the second primary spontaneous pneumothorax raising the debate whether surgical treatment of primary spontaneous pneumothorax should be offered more widely (Chambers and Scarci, 2009).

Surgical management including VATS is relatively safe and results in a definitive treatment of pneumothorax (risk of recurrence of less than $3 \%$ ) through the resection of a bullous lesion, emphysematous pleural blebs and emphysema like changes together with pleurodesis (Chambers and Scarci, 2009). There is no evidence that the size of the blebs affects the rates of recurrence of pneumothorax but recurrence may be higher if bullectomy is performed without pleurodesis $20 \%$ versus $4 \%$, as bullectomy is thought to be unable to remove all the areas of emphysema like changes. It is generally agreed that surgical treatment should be considered in the recurrent ipsilateral pneumothorax, contralateral pneumothorax or bilateral simultaneous pneumothoraces (Baumann et al., 2001; Macduff et al., 2010). Currently surgery is suggested for the management of patients with first primary spontaneous pneumothorax in whom there is persistent air leak lasting for more than 5 to 7 days or in cases with professions at risk such as pilots or those occurring during pregnancy (MacDuff et al., 2010). The literature suggests that VATS is economically justified as an initial treatment option of primary spontaneous pneumothorax (Chou et al., 2003; Rena et al., 2008; Schramel et al., 1996). In fact, there is evidence that VATS may be more effective than intercostal chest drain drainage for treatment of first episode of primary spontaneous pneumothorax resulting in $40 \%$ reduction in costs and reduction in the length of hospital stay (Schramel et al., 1996; Sawada et al., 2005). Pleurodesis with large-particle talc performed during thoracoscopy has been shown to be a safe and cost-effective as well as preventing recurrence of primary spontaneous pneumothorax (Cardillo et al., 2006). There is evidence that talc pleurodesis during medical thoracoscopy may be more cost effective than drainage with intercostal chest drain (Tschopp et al., 2002). Chen at al. (2008) observed that following unsuccessful aspiration of primary spontaneous pneumothorax, VATS compared with chest drain treatment was associated with a shorter hospital stay and lower rates of overall failure and recurrence. Others recommended VATS for the first episode of primary spontaneous pneumothorax if the CT of the thorax identified blebs or bullae (Sawada et al., 2005). Amongst the ACCP panel $15 \%$ of members would consider offering patients a surgical intervention to prevent a recurrence after the first episode of spontaneous pneumothorax. The BTS guidelines suggest that increasingly patient choice may affect the decision whether to proceed with surgical treatment of a first episode of primary spontaneous pneumothorax. Newer techniques for managing primary spontaneous pneumothorax are becoming available such as needlescopic VATS procedure or insertion of endobronchial valves for patients with persistent air leak and these will without doubt influence our treatment strategies for this common problem (Chou et al., 2009).

\section{CONCLUSION}

In conclusion, pleural diseases are common. With new evidence emerging the management of patients with pleural disorders is changing. Increasingly the evidence is provided through randomised controlled studies. Many physicians and surgeons are involved in managing patients with pleural disorders. The main challenge remains in making sure that patients are managed according to the current guidelines. This is probably best achieved if the patients with pleural diseases are treated by specialists with access to a multidisciplinary approach of pleural services. Therefore, clinicians should be aware of the current management options for patients with pleural disorders.

\section{REFERENCES}

Afessa, B., 2000. Pleural effusion and pneumothorax in hospitalized patients with hiv infection*: The pulmonary complications, ICU support and prognostic factors of hospitalized patients with HIV (PIP) study. Chest, 117: 1031-1037. DOI: 10.1378/chest.117.4.1031

Afessa, B., 2001. Pleural effusions and pneumothoraces in AIDS. Curr. Opin. Pulm. Med., 7: 202-209. DOI: 10.1097/00063198-200107000-00007 
Arenas-Jimenez, J., S. Alonso-Charterina, J. SanchezPaya, F. Fernandez-Latorre and S. Gil-Sanchez et al., 2000. Evaluation of CT findings for diagnosis of pleural effusions. Eur. Radiol., 10: 681-690. DOI: 10.1007/s003300050984

Avnon, L.S., M. Abu-Shakra, D. Flusser, D. Heimer and N. Sion-Vardy, 2007. Pleural effusion associated with rheumatoid arthritis: What cell predominance to anticipate? Rheumatol. Int., 27: 919-925. DOI: 10.1007/s00296-007-0322-9

Balbir-Gurman, A., M. Yigla, A.M. Nahir and Y. BraunMoscovici, 2006. Rheumatoid pleural effusion. Semin Arthritis Rheum., 35: 368-378. DOI: 10.1016/j.semarthrit.2006.03.002

Baumann, M.H., C. Strange, J.E. Heffner, R. Light and T.J. Kirby et al., 2001. Management of spontaneous pneumothorax. An American College of Chest Physicians Delphi consensus statement. Chest, 119: 590-602. DOI: 10.1378/chest.119.2.590

Baumann, M.H., R. Nolan, M. Petrini, Y.C. Lee and R.W. Light et al., 2007. Pleural tuberculosis in the United States: Incidence and drug resistance. Chest, 131: 1125-1132. DOI: 10.1378/chest.06-2352

Beck, J.M., 1998. Pleural diseases in patients with acquired immune deficiency syndrome. Clin. Chest Med., 19: 341-349. DOI: 10.1016/S0272-5231(05)70081-2

Bennet, R. and N. Maskell, 2005. Management of malignant pleural effusions. Curr. Opin. Pulm., 11: 296-300.

Bielsa, S., J.M. Porcel, J. Castellote, E. Mas and A. Esquerdaand et al., 2012. Solving the Light's criteria misclassification rate of cardiac and hepatic transudates. Respirology, 17: 721-726. DOI: 10.1111/j.1440-1843.2012.02155.x

Blanc, F.X., K. Atassi, J. Bignon and B. Housset, 2002. Diagnostic value of medical thoracoscopy in pleural disease: A 6-year retrospective study. Chest, 121: 1677-1683. DOI: 10.1378/chest.121.5.1677

Brixey, A.G. and R.W. Light, 2011. Pleural effusions occurring with right heart failure. Curr. Opin. Pulm. Med., 17: 226-231. DOI: 10.1378/chest.121.5.1677

Bynum, L.J. and J.E. Wilson, 1978. Radiographic features of pleural effusions in pulmonary embolism. Am. Rev. Respir. Dis., 117: 829-834. PMID: 655489

Cardillo, G., F. Carleo, R. Giunti, L. Carbone and S. Mariotta et al., 2006. Videothoracoscopic talc poudrage in primary spontaneous pneumothorax: A single-institution experience in 861 cases. J. Thorac. Cardiovasc. Surg., 131: 322-328. DOI: 10.1016/j.jtcvs.2005.10.025
Chambers, A. and M. Scarci, 2009. In patients with firstepisode primary spontaneous pneumothorax is video-assisted thoracoscopic surgery superior to tube thoracostomy alone in terms of time to resolution of pneumothorax and incidence of recurrence? Interact. Cardio Vasc. Thor. Surg., 9: 1003-1008. DOI: 10.1510/icvts.2009.216473

Chapman, S.J. and R.J. Davies, 2004. Recent advances in parapneumonic effusions and empyema. Curr. Opin. Pulm. Med., 10: 299-304. DOI: 10.1097/01.mcp.0000129755.79467.67

Chen, J.S., H.H. Hsu, K.T. Tsai, A. Yuan and W.J. et al., 2008. Salvage for unsuccessful aspiration of primary pneumothorax: Thoracoscopic surgery or chest tube drainage? Ann. Thorac. Surg., 85: 1908-1913. DOI: 10.1016/j.athoracsur.2008.02.038

Chou, S.H., H.P. Li, J.Y. Lee, Y.L. Lee and E.L. Kao et al., 2009. Needlescopic video-assisted thoracic surgery for primary spontaneous pneumothorax. Minim. Invasive. Ther. Allied. Technol., 18: 221224. DOI: $10.1080 / 13645700802649425$

Chou, S.H., Y.J. Cheng and E.L. Kao, 2003. Is videoassisted thoracic surgery indicated in the first episode primary spontaneous pneumothorax? Interact. Cardiovasc. Thorac. Surg., 2: 552-554. DOI: $10.1016 / \mathrm{S} 1569-9293(03) 00143-9$

Davies, C.W., S.E. Kearney, F.V. Gleeson and R.J. Davies, 1999. Predictors of outcome and long-term survival in patients with pleural infection. Am. J. Respir. Crit. Care. Med., 160: 1682-1687. PMID: 10556140

Davies, H.E., R.J. Davies and C.W. Davies, 2010. BTS pleural disease guideline group. Management of pleural infection in adults: British thoracic society pleural disease guideline 2010. Thorax, 65: 41-53. DOI: $10.1136 /$ thx.2010.137000

Dresler, C.M., J. Olak, J.E. Herndon, W.G. Richards and E. Scalzetti et al., 2005. Cooperative Groups Cancer and Leukemia Group B; Eastern Cooperative Oncology Group; North Central Cooperative Oncology Group; Radiation Therapy Oncology Group Phase III intergroup study of talc poudrage Vs talc slurry sclerosis for malignant pleural effusion. Chest, 127: 909-915. DOI: 10.1378/chest.127.3.909

Du Rand, I. and N. Maskell. 2010. Introduction and methods: British thoracic society pleural disease guideline 2010. Thorax, 65: 1-3. DOI: 10.1136/thx.2010.137042 
Fahim, A. and J.A. Kastelik, 2010. The utility of pleural amylase measurement in metastatic mucinous adenocarcinoma. J. R. Coll. Physicians. Edinb., 40: 119-122. DOI: 10.4997/JRCPE.2010.206

Farjah, F., R.G. Symons, B. Krishnadasan, D.E. Wood and R. Flum, 2007. Management of pleural space infections: A populationbased analysis. J. Thorac. Cardiovasc. Surg., 133: 346-351. DOI: 10.1016/j.jtcvs.2006.09.038

Faruqi, S., R. Varma, J.A. Kastelik and M.A. Greenstone, 2006. Spontaneous pneumomediastinum: A rare complication of bronchial asthma. J. Asthma, 46: 969971. DOI: $10.3109 / 02770900903215635$

Feller-Kopman, D., 2009. Pleural ultrasound. Thorax, 64: 97-8.

Ferguson, A.D., R.J. Prescott, J.B. Selkon, D. Watson and C.R Swinburn, 1996. The clinical course and management of thoracic empyema. Q. J. Med., 89: 285-289. DOI: $10.1093 /$ qjmed/89.4.285

Fernandez, C., C. Martin, I. Aranda and S. Romero. 2000. Malignant transient pleural transudate: A sign of early lymphatic tumoral obstruction. Respiration, 67: 333-336. DOI: 10.1159/000029522

Findik, S., L. Erkan, R.W. Light, O. Uzun and A.G. Atici et al., 2008. Massive pulmonary emboli and CT pulmonary angiography. Respiration, 76: 403-412. DOI: $10.1159 / 000147765$

Finley, D.J. and V.W. Rusch, 2011. Anatomy of the pleura. Thorac. Surg. Clin., 21: 157-163. DOI: 10.1016/j.thorsurg.2010.12.001

Gondker, A., S. Pathmanathan and J.A. Kastelik, 2011. Practical procedures: Chemical pleurodesis-what is it and how to do it. Foundation. Years. J., 5: 88-92.

Good, Jr. J.T., D.A. Tayle, R.M. Maulitz, R.L. Kaplan and S.A. Sahn, 1980. The diagnostic value of pleural fluid pH. Chest, 78: 55-59. DOI: 10.1378/chest.78.1.55

Goodman, A. and C.W. Davies, 2006. Efficacy of shortterm versus long-term chest tube drainage following talc slurry pleurodesis in patients with malignant pleural effusions: A randomised trial. Lung. Cancer, 54: 51-55. DOI: 10.1016/j.lungcan.2006.06.004

Grogan, D.R., R.S. Irwin, R. Channick, V. Raptopoulos and F.J. Curley et al., 1990. Complications associated with thoracentesis: A prospective randomized study comparing three different methods. Arch. Intern. Med., 150: 873-877. DOI: 10.1001/archinte.1990.00390160119023

Grundy, S., A. Bentley and J.M.Tschopp, 2012. Primary spontaneous pneumothorax: A diffuse disease of the pleura. Respiration, 83: 185-189. DOI: $10.1159 / 000335993$
Gupta, D., A. Hansell, T. Nichols, T. Duong and J.G. Ayres et al., 2000. Epidemiology of pneumothorax in England. Thorax, 55: 666-671. DOI: 10.1136/thorax.55.8.666

Gur, C., Y. Ilan and O. Shibolet, 2004. Hepatic hydrothorax-pathophysiology, diagnosis and treatment-review of the literature. Liver. Int., 24: 281-284. DOI: 10.1111/j.1478-3231.2004.0936.x

Harris, R.J., M.S. Kavuru, A.C. Mehta, S.V. Medendorp and H.P. Wiedemann et al., 1995. The impact of thoracoscopy on the management of pleural disease. Chest, 107: 845-852. DOI: 10.1378/chest.107.3.845

Haynes, D. and M.H. Baumann, 2011. Pleural controversy: Aetiology of pneumothorax. Respirology, 16: 604-610. DOI: 10.1111/j.14401843.2011.01968.x

Heffner, J.E. and J.S. Klein, 2008. Recent advances in the diagnosis and management of malignant pleural effusions. Mayo. Clin. Proc., 83: 235-250. PMID: 18241636

Heffner, J.E., 2008. Diagnosis and management of malignant pleural effusions. Respirology, 13: 5-20. PMID: 18197908

Heffner, J.E., 2010. Management of the patient with a malignant pleural effusion. Semin. Respir. Crit. Care. Med., 31: 723-733. DOI: 10.1055/s-00301269831

Heffner, J.E., J.S. Klein and C. Hampson, 2010. Diagnostic utility and clinical application of imaging for pleural space infections. Chest, 137: 467-479. DOI: $10.1378 /$ chest.08-3002

Heffner, J.E., L.K. Brown and C.A. Barbieri, 1997. Primary study investigators. Diagnostic value of tests that discriminate between exudative and transudative pleural effusions. Chest, 111: 970-980. DOI: $10.1378 /$ chest.111.4.970

Hooper, C., Y.C. Lee and N. Maskell, 2010b. BTS pleural guideline group investigation of a unilateral pleural effusion in adults: British thoracic society pleural disease guideline 2010. Thorax, 65: 4-17. DOI: $10.1136 /$ thx.2010.136978

Hooper, C.E., Y.C. Lee and N. Maskell, 2010a. Setting up a specialist pleural disease service. Respirology, 15: $1028-1036 . \quad$ DOI: $10.1111 /$ j.14401843.2010.01832.x

Huang, T.W, S.C. Lee and Y.L. Cheng, 2007. Contralateral recurrence of primary spontaneous pneumothorax. Chest, 132: 1146-1150. DOI: 10.1378/chest.06-2772 
Hunninghake, G.W. and A.S. Fauci, 1979. Pulmonary involvement in the collagen vascular diseases. Am. Rev. Respir. Dis., 119: 471-503. PMID: 36018

Janssen, J.P., G. Collier, P. Astoul, G.F. Tassi and M. Noppen et al., 2007. Safety of pleurodesis with talc poudrage in malignant pleural effusion: A prospective cohort study. Lancet, 369: 1535-1539. DOI: $10.1016 / \mathrm{S} 0140-6736(07) 60708-9$

Johnson, J.L., 2000. Pleural effusions in cardiovascular disease. Pearls for correlating the evidence with the cause. Postgrad. Med., 107: 95-101. DOI: 10.3810/pgm.2000.04.998

Jones, P.W. J.P. Moyers, J.T. Rogers, R.M. Rodriguez and Y.C. Lee et al., 2003. Ultrasound-guided thoracentesis: Is it a safer method? Chest, 123: 418423. DOI: $10.1378 /$ chest.123.2.418

Kalomenidis, I. and R.W. Light, 2003. Light. Eosinophilic pleural effusions. Curr. Opin. Pulm. Med., 9: 254-260. DOI: 10.1097/00063198200307000-00002

Kastelik, J.A. and A. Arnold, 2012. Thoracic ultrasonography. Chest, 141: 1366-1366. DOI: 10.1378/chest.11-3067

Kastelik, J.A., I. Aziz, M.A. Greenstone, R. Thompson and A.H. Morice, 2002. Pergolide-induced lung disease in patients with Parkinson's disease. Respir. Med., 96: 548-550. DOI: 10.1053/rmed.2002.1310

Kastelik, J.A., S. Faruqi, R. Teoh and A.G. Arnold, 2009. Thoracic ultrasound: An important skill for respiratory physicians. Thorax, 64: 825-826. DOI: 10.1136/thx.2009.115378

Kinasewitz, G.T. and J.I. Keddissi, 2003. Hepatic hydrothorax. Curr. Opin Pulm Med., 9: 261-265. DOI: 10.1097/00063198-200307000-00003

Koenig, S.J., M. Narasimhan and P.H. Mayo, 2011. Thoracic ultrasonography for the pulmonary specialist. Chest, 140: 1332-1341. DOI: 10.1378/chest.11-0348

Kutty, C.P. and B. Varkey, 1978. "Contarini's condition:" bilateral pleural effusions with markedly different characteristics. Chest, 74: 679-680. DOI: 10.1378/chest.74.6.679

Lanken, P.N., P.B. Terry, H.M. Delisser, B.F. Fahy and J. Hansen-Flaschen et al., 2008. Ats end-of-life care task force. An official American thoracic society clinical policy statement: Palliative care for patients with respiratory diseases and critical illnesses. Am. J. Respir. Crit. Care. Med., 177: 912-927. DOI: 10.1164/rccm.200605-587ST

Lawton, F., G. Blackledge and R. Johnson, 1985. Coexistent chylous and serous pleural effusions associated with ovarian cancer: A case report of Contarini's syndrome. Eur. J. Surg. Oncol., 11: 177178. PMID: 4007175
Lee, P., P.N. Mathur and H.G. Colt, 2010. Advances in thoracoscopy: 100 years since Jacobaeus. Respiration, 79: 177-186. DOI: 10.1159/000268617

Light, R.W., 1995. A new classification of parapneumonic effusions and empyema. Chest, 108: 299-301. DOI: 10.1378/chest.108.2.299

Light, R.W., 1997. Diagnostic principles in pleural disease. Eur. Respir. J., 10: 476-481. DOI: 10.1183/09031936.97.10020476

Light, R.W., 2002. Clinical practice. Pleural effusion. N. Engl. J. Med., 346: 1971-1977. DOI: 10.1056/NEJMcp010731

Light, R.W., 2006a. The undiagnosed pleural effusion. Clin. Chest. Med., 27: 309-319. DOI: 10.1016/j.ccm.2005.12.002

Light, R.W., 2006b. Parapneumonic effusions and empyema. Proc. Am. Thorac. Soc., 3: 75-80. DOI: 10.1513/pats.200510-113JH

Light, R.W., 2010. Pleural effusion in pulmonary embolism. Semin. Respir. Crit. Care. Med., 31: 716722. DOI: $10.1055 / \mathrm{s}-0030-1269832$

Light, R.W., 2011a. Pleural effusions. Med Clin North Am., $\quad$ 95: 1055-1070. DOI: 10.1016/j.mcna.2011.08.005

Light, R.W., 2011b. Pleural controversy: Optimal chest tube size for drainage. Respirology, 16: 244-288. DOI: $10.1111 /$ j.1440-1843.2010.01913.x

Light, R.W., J.T. Rogers, D. Cheng and R.M. Rodriguez, 1999. Large pleural effusions occurring after coronary artery bypass grafting. Cardiovascular surgery associates, PC. Ann. Intern. Med., 130: 891896. PMID: 10375337

Light, R.W., M.I. Macgregor, P.C. Luchsinger and W.C. Ball Jr., 1972. Pleural effusions: the diagnostic separation of transudates and exudates. Ann. Intern. Med., 77: 507-513. PMID: 4642731

Luo, Y.F., I.M. Robbins, M. Karatas, A.G. Brixey and T.W. Rice et al., 2011. Frequency of pleural effusions in patients with pulmonary arterial hypertension associated with connective tissue diseases. Chest, 140: 42-47. DOI: 10.1378/chest.10-0227

MacDuff, A., A. Arnold and J. Harvey, 2010. Management of spontaneous pneumothorax: British thoracic society pleural disease guideline 2010. BTS pleural disease guideline group. Thorax, 65: 18-31. DOI: $10.1136 /$ thx.2010.136986

Marel, M., M. Zrustova, B. Stastny and R.W. Light, 1993. The incidence of pleural effusion in a welldefined region: Epidemiologic study in central Bohemia. Chest, 4: 1486-1489. DOI: 10.1378/chest.104.5.1486 
Martinez-Garcia, M.A., E. Cases-Viedma, P.J. CorderoRodriguez, M. Hidalgo-Ramírez and M. PerpinaTordera et al., 2000. Diagnostic utility of eosinophils in the pleural fluid. Eur. Respir. J., 15: 166-169. DOI: 10.1183/09031936.00.15116600

Maskell, N.A., C.W. Davies, A.J. Nunn, E.L. Hedley and F.V. Gleeson et al., 2005. U.K. controlled trial of intrapleural streptokinase for pleural infection. N. Engl. J. Med., 352: 865-874. DOI: 10.1056/NEJMoa042473

Maskell, N.A., S. Batt, E.L. Hedley, C.W. Davies and S.H. Gillespie et al., 2006. The bacteriology of pleural infection by genetic and standard methods and its mortality significance. Am. J. Respir. Crit. Care. Med., 174: 817-823. DOI: 10.1164/rccm.200601-074OC

Melton, L.J., N.G. Hepper and K.P. Offord, 1979. Incidence of spontaneous pneumothorax in Olmested County, Minnesota: 1950-1974. Am. Rev. Respir. Dis., 120: 1379-1382. PMID: 517861

Menzies, S.M., N.M. Rahman, J.M. Wrightson, H.E. Davies and R. Shorten et al., 2011. Blood culture bottle culture of pleural fluid in pleural infection. Thorax, 66: 658-562. DOI: 10.1136/thx.2010.157842

Milanez De Campos, J.R., L.O. Filho, E.D.C. Werebe, H. Sette Jr. and A. Fernandez et al., 2000. Thoracoscopy and talc poudrage in the management of hepatic hydrothorax. Chest, 118: 13-7. DOI: 10.1378/chest.118.1.13

Noppen, M., 2001. Normal volume and cellular contents of pleural fluid. Curr. Opin. Pulm. Med., 7: 180-182. DOI: $10.1097 / 00063198-200107000-00002$

Petrakis, I.E., J.E. Heffner and J.S. Klein, 2010. Surgery should be the first line of treatment for empyema. Respirology, 15: 202-207. DOI: 10.1111/j.14401843.2009.01677.x

Phillip, W., P.W. Jones, J.P. Moyers, J.T. Rogers and R.M. Rodriguez et al., 2003. Ultrasound-guided thoracentesis: Is it a safer method? Chest, 123: 418423. PMID: 12576360

Pines, A., N. Kaplinsky, D. Olchovsky, J. Rozenman and O. Frankl, 1985. Pleuro-pulmonary manifestations of systemic lupus erythematosus: Clinical features of its subgroups. Prognostic and therapeutic implications. Chest, 88: 129-135. DOI: 10.1378/chest.88.1.129

Porcel, J.M. and M. Vives, 2006. Distribution of pleural effusion in congestive heart failure. South. Med. J., 99: 98-99.

DOI: 10.1097/01.smj.0000199278.81401.2f
Porcel, J.M. and R.W. Light, 2006. Diagnostic approach to pleural effusion in adults. Am. Fam. Physician, 73: 1211-1220. PMID: 16623208

Porcel, J.M. and R.W. Light, 2008. Pleural effusions due to pulmonary embolism. Curr. Opin. Pulm. Med., 14: 337-342. DOI: 10.1097/MCP.0b013e3282fcea3c

Porcel, J.M., A.B. Madroñero, M. Pardina, M. Vives and A. Esquerda et al., 2007. Analysis of pleural effusions in acute pulmonary embolism: Radiological and pleural fluid data from 230 patients. Respirology, 12: 234-139. DOI: 10.1111/j.1440-1843.2006.01026.x

Porcel, J.M., M. Vives, G. Cao, A. Esquerda and M. Rubio et al., 2004. Measurement of pro-brain natriuretic peptide in pleural fluid for the diagnosis of pleural effusions due to heart failure. Am. J. Med., 116: 417-420. DOI: 10.1016/j.amjmed.2003.11.008

Porcel, J.M., M.C. Civit, S. Bielsa and R.W. Light, 2012. Contarini's syndrome: Bilateral pleural effusion, each side from different causes. J. Hosp. Med., 7: 164-165. DOI: $10.1002 / \mathrm{jhm} .981$

Putnam, Jr. J.B., G.L. Walsh, S.G. Swisher, J.A. Roth and D.M. Suell et al., 2000. Outpatient management of malignant pleural effusion by a chronic indwelling pleural catheter. Ann. Thorac. Surg., 69: 369-375. DOI: 10.1016/S0003-4975(99)01482-4

Qureshi, N.R., N.M. Rahman and F.V. Gleeson, 2009. Thoracic ultrasound in the diagnosis of malignant pleural effusion. Thorax, 64: 139-43. DOI: 10.1136/thx.2008.100545

Rahman, N.M., N.A. Maskell, A. West, R. Teoh and A. Arnold et al., 2011. Intrapleural use of tissue plasminogen activator and DNase in pleural infection. N Engl. J. Med., 365: 518-526.

Rahman, N.M., N.J. Ali, G. Brown, S.J. Chapman and R.J. Davies et al., 2010. British thoracic society pleural disease guideline group. Local anaesthetic thoracoscopy: British thoracic society pleural disease guideline 2010. Thorax, 65: 54-60. DOI: 10.1136/thx.2010.137018

Reddy, C., A. Ernst, C. Lamb and D. Feller-Kopman, 2011. Rapid pleurodesis for malignant pleural effusions: A pilot study. Chest, 139: 1419-1423. DOI: $10.1378 /$ chest.10-1868

Rena, O., F. Massera, E. Papalia, C.D. Pona and M. Robustellini et al., 2008. Surgical pleurodesis for Vanderschueren's stage III primary spontaneous pneumothorax. Eur. Respir. J., 31: 837-841. DOI: 10.1183/09031936.00140806 
Roberts, M.E., E. Neville, R.G. Berrisford, G. Antunes and N.J. Ali, 2010. bts pleural disease guideline group management of a malignant pleural effusion: British thoracic society pleural disease guideline 2010. Thorax, 65: 32-40. DOI: $10.1136 /$ thx.2010.136994

Rodriguez-Panadero, F. and A. Montes-Worboys, 2012. Mechanisms of pleurodesis. Respiration, 83: 91-98. DOI: $10.1159 / 000335419$

Rodriguez-Panadero, F. and B. Romero-Romero, 2011. Management of malignant pleural effusions. Curr. Opin. Pulm. Med., 17: 269-273. DOI: 10.1097/MCP.0b013e3283474015

Rodriguez-Panadero, F., 2008. Medical thoracoscopy. Respiration, 76: 363-372. DOI: 10.1159/000158545

Rodriguez-Panadero, F., J.P. Janssen and P. Astoul, 2006. Thoracoscopy: General overview and place in the diagnosis and management of pleural effusion. Eur. Respir. J., 28: 409-422. DOI: 10.1183/09031936.06.00013706

Romero, S., A. Martinez, L. Hernandez, C. Fernandez and A. Espasa et al., 2000. Light's criteria revisited: Consistency and comparison with new proposed alternative criteria for separating pleural transudates from exudates. Respiration, 67: 18-23. DOI: $10.1159 / 000029457$

Sahn, S.A., 1993. Management of complicated parapneumonic effusions. Am. Rev. Respir. Dis., 148: 813-817. DOI: $10.1164 /$ ajrccm/148.3.813

Sahn, S.A., 1995. The diagnostic value of pleural fluid analysis. Semin. Respir. Crit. Care., 16: 269-278. DOI: $10.1055 / \mathrm{s}-2007-1009837$

Sakuraba, M., K. Masuda, A. Hebisawa, Y. Sagara and H. Komatsu, 2006. Diagnostic value of thoracoscopic pleural biopsy for pleurisy under local anaesthesia. ANZ. J. Surg., 76: 722-274. DOI: 10.1111/j.1445-2197.2006.03839.x

Sawada, S., Y. Watanabe and S. Moriyama, 2005. Video-assisted thoracoscopic surgery for primary spontaneous pneumothorax: Evaluation of indications and long-term outcome compared with conservative treatment and open thoracotomy. Chest, 127: 2226-2230. DOI: 10.1378/chest.127.6.2226

Schramel, F.M., T.G. Sutedja, J.C. Braber, J.C.v. mourik and P.E. Postmus, 1996. Cost-effectiveness of video-assisted thoracoscopic surgery versus conservative treatment for first time or recurrent spontaneous pneumothorax. Eur. Respir. J., 9: 18211825. DOI: $10.1183 / 09031936.96 .09091821$
Shaw, P. and R. Agarwal, 2004. Pleurodesis for malignant pleural effusions. Cochrane. Database. Syst. Rev., 1: CD002916. PMID: 14973997

Sihoe, A.D.L., A.P.C. Yim, T.W. Lee, S. Wan and E.H. Yuen et al., 2000. Can CT scanning be used to select patients with unilateral primary spontaneous pneumothorax for bilateral surgery? Chest, 118: 380-383. DOI: 10.1378/chest.118.2.380

Skouras, V., A. Awdankiewicz and R.W. Light, 2010. What size parapneumonic effusions should be sampled? Thorax, 65: 91-91. DOI: 10.1136/thx.2008.112797

Spiegler, P.A., A.N. Hurewitz and M.L. Groth, 2003. Rapid pleurodesis for malignant pleural effusions. Chest, 123: 1895-1898. DOI: 10.1378/chest.123.6.1895

Townshend, A.P., W. Speake and A. Brooks, 2007. Chylothorax. Emerg. Med. J., 24: e11-e11. DOI: 10.1136/emj.2006.042028

Tschopp, J.M., C. Boutin, P. Astoul, J.P. Janssen and S. Grandin et al., 2002. ESMEVAT team. (European Study on Medical Video-Assisted Thoracoscopy) Talcage by medical thoracoscopy for primary spontaneous pneumothorax is more cost-effective than drainage: A randomised study. Eur. Respir. J., 20: 1003-1009. DOI: 10.1183/09031936.02.00278202

Tschopp, J.M., R. Rami-Porta, M. Noppen and P. Astoul, 2006. Management of spontaneous pneumothorax: state of the art. Eur. Respir. J., 28: 637-650. DOI: 10.1183/09031936.06.00014206

Van Meter, M.E., K.Y. McKee and R.J. Kohlwes, 2011. Efficacy and safety of tunneled pleural catheters in adults with malignant pleural effusions: A systematic review. J. Gen. Intern. Med., 26: 70-76. DOI: $10.1007 / \mathrm{s} 11606-010-1472-0$

Viallat, J.R., F. Rey, P. Astoul and C. Boutin, 1996. Thoracoscopic talc poudrage pleurodesis for malignant effusions. A review of 360 cases. Chest, 110: 1387-1393. DOI: 10.1378/chest.110.6.1387

Wrightson, J.M. and N.A. Maskell, 2012. Pleural infection. Clin. Med., 12: 82-86. PMID: 22372232 